\title{
STRUCTURAL, VIBRATIONAL, OPTICAL, AND MAGNETIC PROPERTIES OF 0-3 TYPE PARTICULATE $\mathrm{PbTiO}_{3}-\mathrm{NiFe}_{2} \mathrm{O}_{4}$ COMPOSITES
}

\author{
Pham Do Chung ${ }^{a *}$, Le Thi Mai Oanh ${ }^{\mathrm{a}, \mathrm{b}}$, Nguyen Van Minha, b \\ ${ }^{a}$ Department of Physics, Hanoi National University of Education, Hanoi, Vietnam \\ ${ }^{b}$ Center for Nano Science and Technology, Hanoi, Vietnam \\ "Corresponding author: Email: chungpd@hnue.edu.vn
}

\author{
Article history \\ Received: June $16^{\text {th }}, 2021$ \\ Received in revised form: August $5^{\text {th }}, 2021 \mid$ Accepted: August $6^{\text {th }}, 2021$ \\ Available online: October $4^{\text {th }}, 2021$
}

\begin{abstract}
We synthesized 0-3 type (1-x) $\mathrm{PbTiO}_{3}-x \mathrm{NiFe}_{2} \mathrm{O}_{4}(x=0.0-0.5)$ multiferroic composites with two independently crystallized parent phases by the sol-gel method. Structural, surface morphology, vibrational, optical, and magnetic characteristics were investigated by X-ray diffraction (XRD), SEM, Raman scattering, UV-vis absorption, and magnetization (M-H) measurements, respectively. The XRD result showed that the lattice parameter a of the $\mathrm{PbTiO}_{3}(\mathrm{PTO})$ phase decreased while lattice parameter c increased after compositing, leading to a decrease in the tetragonal ratio c/a. SEM images indicated that the $\mathrm{NiFe}_{2} \mathrm{O}_{4}$ (NFO) crystals that crystallized later are small and adhere to the surface of the large PTO particles. The strong cohesion between the two components was also revealed by the gradual shift of the Raman peaks to the lower wavelength and the reduction of the Raman intensity as the NFO content increased. The UV-vis absorption result showed the coabsorption spectra of the parent phases in the composites. Magnetization curves presented a sharp increase in saturation magnetization $M_{S}$ with NFO content from 0.014 emu/g for the PTO sample to $14.360 \mathrm{emu} / \mathrm{g}$ for the composite containing $50 \mathrm{~mol} \%$ NFO. This study indicates an effective method in the search for multilayer composites.
\end{abstract}

Keywords: Composites; Magnetization; Parent phase.

DOI: http://dx.doi.org/10.37569/DalatUniversity.11.4.911(2021)

Article type: (peer-reviewed) Full-length research article

Copyright @ 2021 The author(s).

Licensing: This article is licensed under a CC BY-NC 4.0 


\section{INTRODUCTION}

Multiferroic composites that comprise ferroelectric and ferro/ferrimagnetic phases have drawn a large research interest due to their magnetoelectric (ME) effect (G. Liu et al., 2005; Loyau et al., 2015; Palneedi et al., 2016; Pereira et al., 2020). Unlike single phase multiferroics that possess an intrinsic ME effect with a weak ME coupling coefficient, multiferroic composites show a much larger coupling (Fiebig, 2005; Pereira et al., 2020; Zeng et al., 2020). Previous reports suggested that ME coupling in multiferroic composites occurs extrinsically in three different ways mediated through (i) strain, (ii) charge carrier, and (iii) spin exchange, of which the second has recently been studied intensively and widely (Palneedi et al., 2016; Pereira et al., 2020). The strainmediated ME coupling in composites is a consequence of elastic interaction between magnetostrictive and piezoelectric components (Bichurin \& Petrov, 2010; Tsai et al., 2013) that enables the dielectric polarization $P$ to be controlled by applied magnetic field $\mathrm{H}$ and vice versa change the magnetization $\mathrm{M}$ by adjusting the external electric field $\mathrm{E}$.

In a multiferroic composite, the grain boundary interface between two components has an important role in mediating elastic interaction; hence, it directly affects the ME effect in composites. To fabricate a multiferroic composite with a large $\mathrm{ME}$ coefficient, it is necessary to create a good quality grain boundary junction between crystal particles that possesses good interfacial stress while still maintaining the ferromagnetic and ferroelectric properties of the two parent phases. Accordingly, ME coupling strength is strongly related to the geometric structure between the parent phases, such as in composites with dispersed particles (0-3 type) (Ahlawat et al., 2016), or composites with layer (2-2 type) (Murakami et al., 2005), fibrous/rod (Bichurin \& Petrov, 2010) or core-shell structures (Schileo, 2013; Shvartsman et al., 2011). In addition, the crystallization process also affects interface quality. For the 0-3 type structure, previous reports showed three major methods for processing composites, which are (i) two parent phases are instantaneously crystallized in the same condition (X. Liu et al., 2005), (ii) composites are created by mechanically mixing two parent phases (Adhlakha et al., 2015), and (iii) the second phase is crystallized in the presence of another crystalline phase (Wang et al., 2013). The first method ensures a good grain boundary junction while causing cations to move between the two parent phases, leading to difficulty in retaining the ferromagnetic and ferroelectric properties. The second well maintains the physical properties of the parent phases but creates a weak interfacial stress because only a mechanical mixing process is used. We hope that the third process can avoid the disadvantages of the first two methods.

We report herein properties of particulate $(1-\mathrm{x}) \mathrm{PbTiO}_{3}-\mathrm{xNiFe}_{2} \mathrm{O}_{4}(\mathrm{x}=0.0-0.5)$ multiferroic composites in which $\mathrm{PbTiO}_{3}$ (PTO) nanoparticles were crystallized previously and mixed with $\mathrm{NiFe}_{2} \mathrm{O}_{4}$ (NFO) gel. Thus, the PTO phase is dispersed in the NFO matrix forming a 0-3 type structure. The effect of NFO content on the structural, vibrational, optical, and magnetic properties of the composites was evaluated. The results show that this fabrication method is beneficial for the synthesis of multiferroic 
composites that possess both high-quality grain boundary junctions and well-maintained ferroelectric and ferromagnetic properties of the constituent phases.

\section{EXPERIMENT}

The 0-3 type (1-x) $\mathrm{PbTiO}_{3}-\mathrm{xNiFe}_{2} \mathrm{O}_{4}(\mathrm{x}=0.0-0.5)$ multiferroic composites were fabricated by the sol-gel method. To form PTO sol, a solution of citric acid and ethylene glycol in mol ratio 6:4 was prepared previously. Titanium tetraisopropoxide $\left(\mathrm{Ti}\left[\left(\mathrm{CH}_{3}\right)_{2} \mathrm{CHO}\right]_{4}\right)$ was added to this solution and then dissolved by stirring at $90^{\circ} \mathrm{C}$ for $2 \mathrm{~h}$. Lead nitrate $\left(\mathrm{Pb}\left(\mathrm{NO}_{3}\right)_{2} \cdot 6 \mathrm{H}_{2} \mathrm{O}\right)$ was added to the solution containing $\mathrm{Ti}^{4+}$. The mixture was stirred until a colorless transparent solution was obtained. Water molecules were evaporated by stirring at $90^{\circ} \mathrm{C}$ until a wet gel was achieved. We dried the wet gel at $180^{\circ} \mathrm{C}$ in an oven to get a dark brown gel. Finally, PTO nanoparticles were produced by calcining the dry gel at $800^{\circ} \mathrm{C}$ for $2 \mathrm{~h}$ in air. In order to fabricate composites, PTO nanoparticles were mixed into NFO sol, which was prepared by dissolving $\mathrm{Ni}\left(\mathrm{NO}_{3}\right)_{2} .2 \mathrm{H}_{2} \mathrm{O}$ and $\mathrm{Fe}\left(\mathrm{NO}_{3}\right)_{3} .9 \mathrm{H}_{2} \mathrm{O}$ in a similar citric acid/ethylene glycol solution. The mol ratios between PTO and NFO were 90:10, 80:20, 70:30, 60:40, and 50:50, hereafter referred to as PN1, PN2, PN3, PN4, and PN5, respectively. Final composites were achieved by calcining the composite gel at $800^{\circ} \mathrm{C}$ for $2 \mathrm{~h}$ in air.

To characterize the physical properties of the composites, we performed a series of X-ray diffraction (XRD), SEM, Raman scattering, UV-vis absorption, and vibrating sample magnetometer (VSM) measurements. The XRD measurements were carried out using a D5005 diffractometer employing $\mathrm{CuK} \alpha$ radiation. Field emission scanning electron microscopes (FE-SEM, Hitachi, S-4800, Japan) were used to examine the microstructure of the composites. Raman spectra of the composites were obtained using a LabRAM HR800 Raman spectrometer (HORIBA Jobin-Yvon, France) excited by a $632.8 \mathrm{~nm}$ helium-neon laser. The absorption spectra were recorded with a Jasco V670 photospectrometer using an integral sphere configuration in the wavelength band of 200-1000 nm. Magnetic measurements were performed at room temperature using a vibrating sample magnetometer with a maximum magnetic field of $13 \mathrm{kOe}$.

\section{RESULTS AND DISCUSSION}

Figure 1 shows XRD patterns for PTO-NFO composites of different NFO content $(0,10,20,30,40$, and 50\%). The bottom pattern of the PTO sample matches well with JCPDS card No. 77-2002, showing that the fabricated material, $\mathrm{PbTiO}_{3}$, is well crystallized in a tetragonal structure with lattice parameters $a \sim 3.910$ and $c \sim 4.115 \AA$ (tetragonal ratio $c / a \sim 1.052$ ). The top pattern is consistent with JCPDS card No. 742081, indicating that the NFO sample crystallized in a face-centered cubic structure with lattice constant $a \sim 8.337 \AA$. Composites present two collections of reflexes that belong to only one of two parent phases, PTO or NFO. The intensity of the XRD peaks increases gradually with NFO content. As is well known, the large separation of the (101) and (110) reflexes shows a high tetragonality (large $c / a$ ratio) for the PTO phase. The expanded scale portion of Figure 1a compares the positions of the (101) and (110) reflexes. The reflexes clearly overlap more with increasing NFO content, resulting in a 
decrease in the $c / a$ ratio, as shown in Figure $1 \mathrm{~b}$ ( $c / a \sim 1.037$ for composites). This shows that the NFO phase, although formed later, has a certain influence on the crystal structure of PTO, possibility originating from the elastic stress between the two phases.
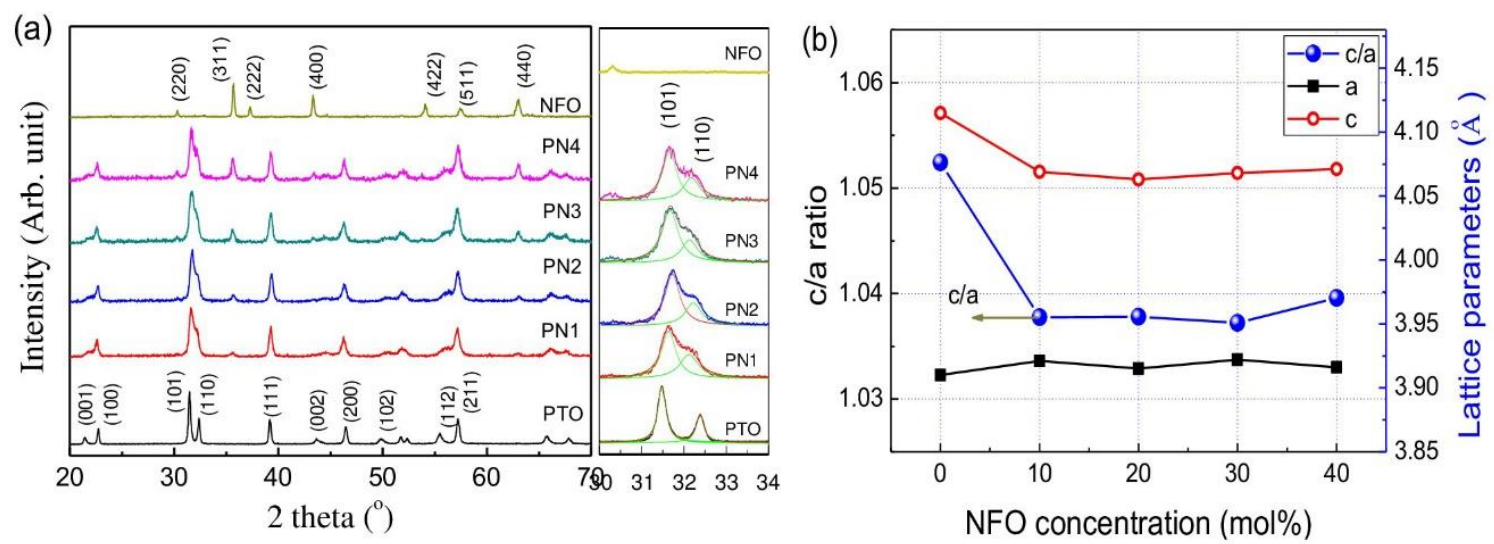

Figure 1. (a) X-ray diffraction (XRD) patterns of as-synthesized (1-x) $\mathrm{PbTiO}_{3}-\mathrm{xNiFe}_{2} \mathrm{O}_{4}$ $(x=0.0-0.5)$ composites (scale expanded to show (101) and (110) reflexes) and (b) lattice parameters and tetragonal ratio of composites as a function of NFO content

Figure 2a presents SEM images of PTO, including nanoparticles with definite shapes, smooth surfaces, clear grain boundaries, and sizes in the range of 40-70 nm. The surface morphology of the PN3 composite in Figure 2b shows that the grain boundaries become less clear, and particles as large as several tens of nanometers appear to adhere. In addition, their surfaces are covered with small particles about $10 \mathrm{~nm}$ in size, resulting in a rough surface. Since the synthesis of NFO crystals takes place later than that of PTO, it can be assumed that the small observed particles are NFO particles. To clarify this, an SEM image of the NFO sample was taken and is inset in Figure 2b, thereby confirming that the above statement is correct.

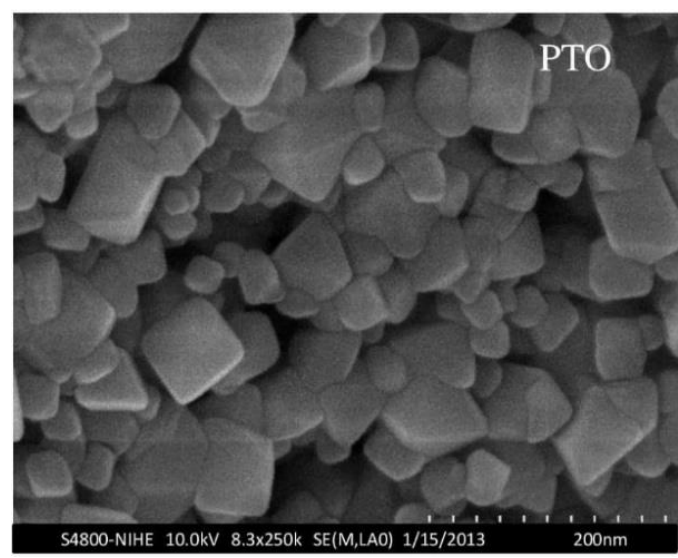

(a)

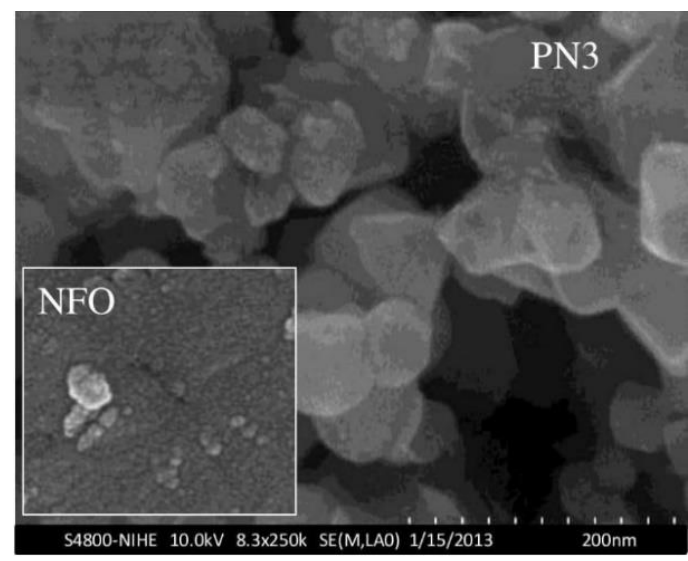

(b)

Figure 2. SEM images of as-synthesized $\mathrm{PbTiO}_{3}$ and $0.8 \mathrm{PbTiO}_{3}-\mathrm{O}_{2} \mathrm{NiFe}_{2} \mathrm{O}_{4}$ composite (inset figure is an $\mathrm{SEM}$ image of the $\mathrm{NiFe}_{2} \mathrm{O}_{4}$ sample)

Note: a) PTO and b) PN3. 
Raman scattering spectra of composites with different NFO contents are shown in Figure 3. In the wave number range from $150 \mathrm{~cm}^{-1}$ to $900 \mathrm{~cm}^{-1}$, the PTO sample exhibited eight Raman peaks while the NFO sample presented five peaks, which were assigned to Raman active modes, as shown in Figure 2. Similar to the XRD results, the composites also displayed Raman peaks belonging to both parent phases. It is clear that some peaks corresponding to the PTO phase, such as E(2TO), E(3TO), and E(3LO), shifted gradually to smaller wave number (shown by arrows) while others remained almost unchanged as NFO content increased. This shift can be well explained by the phase transition from tetragonal to cubic structure, as reported by Burns and Scott (1973), which is consistent with the sharp decrease in the observed $c / a$ ratio. Thus, Raman scattering spectra also indirectly reflect the change in crystal structure of the PTO phase, which is consistent with the XRD results and confirms that the two parent phases have a close mechanical interaction beneficial for a good magnetoelectric ME coupling.

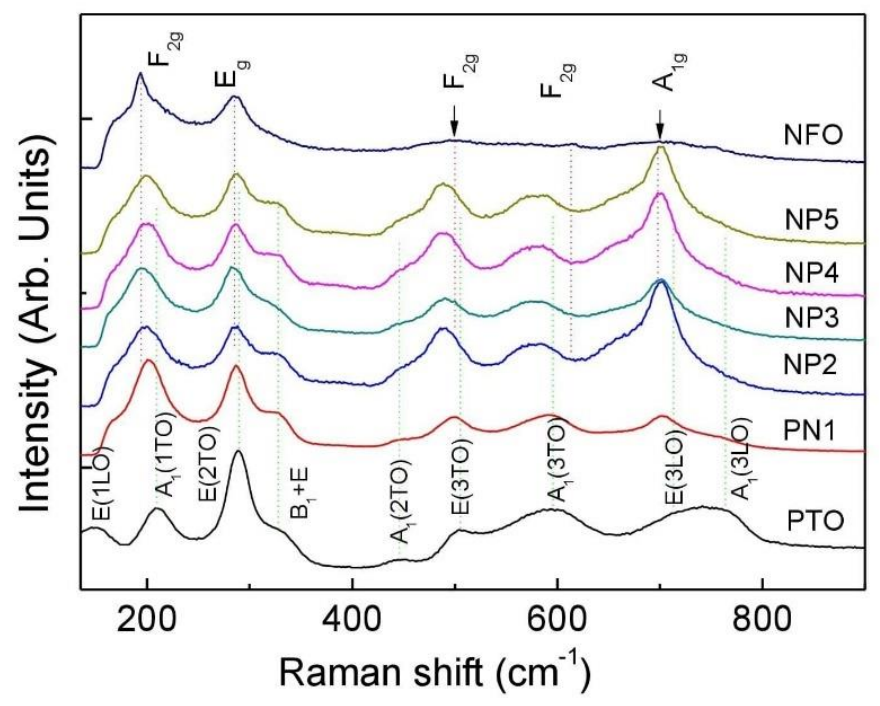

Figure 3. Raman scattering of as-synthesized (1-x)PbTiO $3-\mathrm{xNiFe}_{2} \mathrm{O}_{4}(x=0.0-0.5)$ composites

Figure 4 shows diffuse reflectance UV-vis absorption spectra of composites with different NFO contents. The absorption edge of the PTO sample was around $420 \mathrm{~nm}$ while that of NFO was about $750 \mathrm{~nm}$. The composites exhibit increasing absorbance in the $400-700 \mathrm{~nm}$ range with increases in NFO content. It is clear that the composites exhibit total absorbance of the two parent phases, PTO and NFO, where the 400-700 nm absorption region can be assigned to the contribution of the NFO phase. Using a Wood-Tauc plot representing $(\alpha h v)^{2}$ as a function of photon energy (hv) for a direct band gap semiconductor (Figure 4b), effective band gap energies of about 3.00, 1.78, 1.60 , and $1.42 \mathrm{eV}$ were found for PTO, PN1, PN4, and NFO, respectively. These values agree well with those reported in previous studies for PTO powder (Moret et al., 2002; Zheng et al., 2016) and NFO (Dileep et al., 2014; Meinert \& Reiss, 2014). 


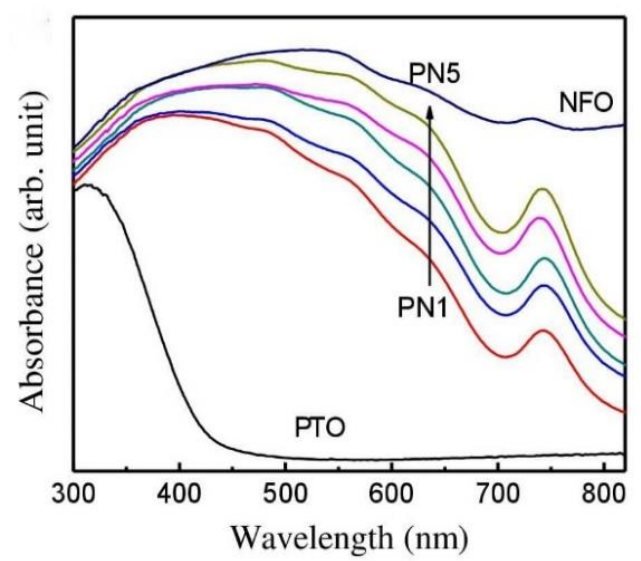

(a)

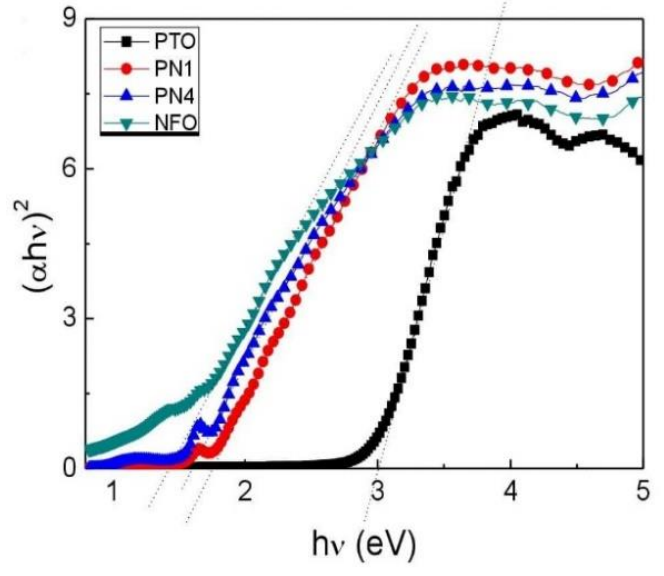

(b)

Figure 4. (a) Absorption spectra of $(1-x) \mathrm{PbTiO}_{3}-\mathrm{xNiFe}_{2} \mathrm{O}_{4}(x=0.0-0.5)$ composites and (b) method to determine the energy bandgap $E_{g}$ from the plot of $(\alpha \mathrm{hv})^{2}$ as a function of photon energy

Magnetic characteristics of the composites were determined by magnetization measurements at room temperature, as shown in Figure 5a. The inset figure in Figure 5a presents the M-H hysteresis loop of the PTO phase, which indicates that PTO possessed both intrinsic diamagnetic and weak ferromagnetic orders. The diamagnetic property is well known as the consequence of $3 \mathrm{~d}^{0}$ electron configuration of $\mathrm{Ti}^{4+}$ cations in the PTO crystal, which results in zero magnetic momentum (Le et al., 2015; Ren et al., 2007; Zhou et al., 2015). The weak ferromagnetic order was attributed to oxygen vacancies that appeared inside the PTO crystal during the production process (Shimada et al., 2012a, 2012b). The saturation magnetization $\mathrm{M}_{\mathrm{S}}$ was determined to be about $0.014 \mathrm{emu} / \mathrm{g}$ and $45 \mathrm{emu} / \mathrm{g}$ for PTO and NFO, respectively. Thus, PTO can be considered a nonmagnetic phase compared to NFO.

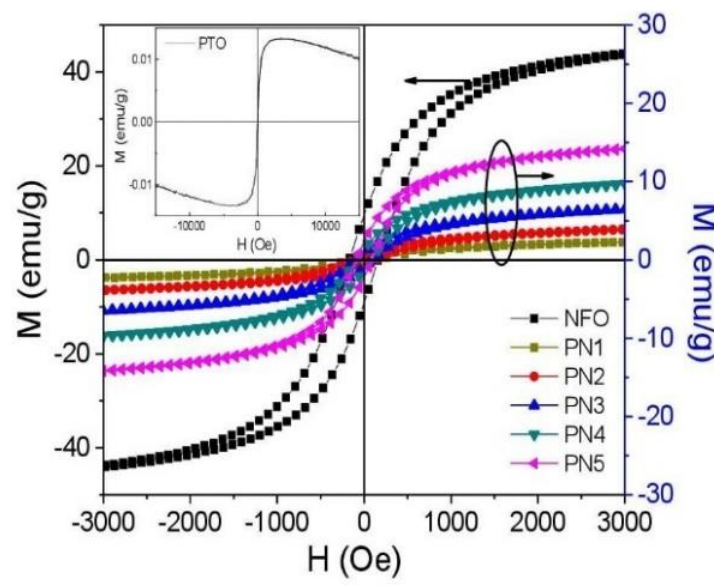

(a)

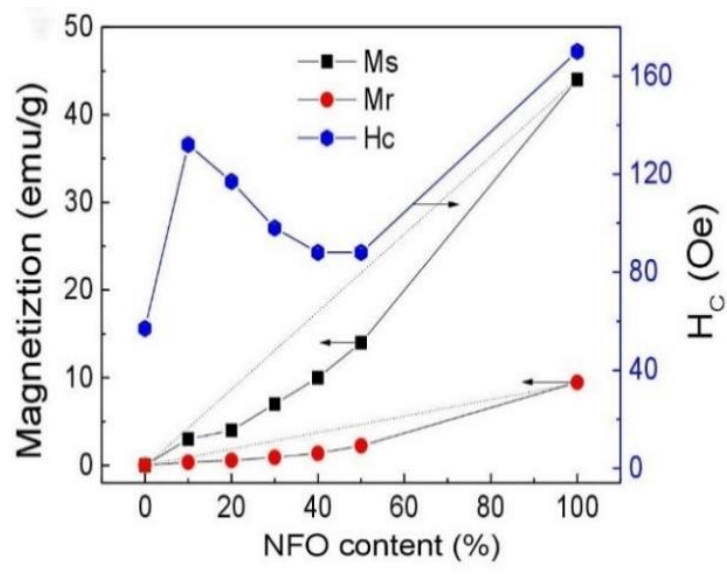

(b)

Figure 5. (a) M-H hysteresis loops of PTO, composites, and NFO samples (inset figure shows M-H curve of PTO) and (b) the plot of $M_{s}, M_{r}$, and $H_{c}$ as a function of NFO mole fraction (dotted lines display theoretical $M_{s}$ and $M_{r}$ ) 
Table 1. Magnetic parameters of 0-3 type (1-x) $\mathrm{PbTiO}_{3}-\mathrm{xNiFe}_{2} \mathrm{O}_{4}(x=0.0-0.5)$ multiferroic composites

\begin{tabular}{llllllll}
\hline Samples & PTO & PN1 & PN2 & PN3 & PN4 & PN5 & NFO \\
\hline Ms observed (emu/g) & 0.014 & 3 & 4 & 7 & 10 & 14 & 45 \\
Ms theory (emu/g) & 0.014 & 4.5 & 9 & 13.5 & 18 & 22.5 & 45 \\
Mr observed (emu/g) & 0 & 0.36 & 0.58 & 0.92 & 1.37 & 2.25 & 9.47 \\
Hc observed (Oe) & - & 132 & 117 & 98 & 88 & 88 & 170 \\
\hline
\end{tabular}

In composites, both saturation magnetization $\mathrm{M}_{\mathrm{s}}$ and remanent magnetization $\mathrm{M}_{\mathrm{r}}$ increased with NFO content, as graphed in Figure 5b (Table 1). This behavior reflects the magnetic dilution effect that occurs when the ferrimagnetic NFO phase is incorporated into the PTO phase. It is obvious that the dependence of $\mathrm{M}_{\mathrm{s}}$ and $\mathrm{M}_{\mathrm{r}}$ on NFO mole fraction (solid square curve and empty circle curve) is not consistent with the theoretical calculation results (dotted lines) obtained using the rule of mixture (sum rule) (Narendra Babu et al., 2011). This mismatch can be attributed to the dispersion of NFO into the matrix of nonmagnetic PTO material, resulting in somewhat greater porosity or a surface effect (Newnham, 1986). This difference can be partly explained as the consequence of the tight cohesion between the two phases at the grain boundaries, resulting in certain changes in the structural and physical properties, as observed above. In addition, Figure $5 \mathrm{~b}$ shows the change in the coercive magnetic field value according to the NFO ratio. It is quite interesting that $\mathrm{H}_{\mathrm{c}}$ increases sharply to 132 Oe for PN1 samples, then decreases gradually with further increases in NFO concentration (Table 1). This can be explained by the fact that the junctions between the two phases contain defects due to ionic substitution between the two phases. Such factors prevent the displacement of magnetic domain walls, resulting in high coercivity $\mathrm{H}_{\mathrm{c}}$. Therefore, when the concentration of the NFO phase is low, the ratio of the area of the grain boundaries to the volume of the NFO magnetic phase is high, leading to a sharply increased $\mathrm{H}_{\mathrm{c}}$ value, as observed in Figure $5 \mathrm{~b}$ for PN1. As the NFO concentration increases further, this ratio decreases, resulting in the observed decrease in $\mathrm{H}_{\mathrm{c}}$.

\section{CONCLUSION}

In summary, 0-3 type (1-x) $\mathrm{PbTiO}_{3}-\mathrm{xNiFe}_{2} \mathrm{O}_{4}(\mathrm{x}=0.0-0.5)$ multiferroic composites were successfully fabricated by the facile two-step sol-gel method. The two parent phases exhibited good grain boundaries even though the phases were independently crystallized. The composites showed a marked improvement in magnetism with increasing NFO content. However, the increase in the rate of saturation magnetization is smaller than the theoretical value, which is considered a consequence of the interplay between the two phases. The results can be considered a good sign in the search for multiferroic composites that possess good elastic interaction between ferroelectric and ferromagnetic phases due to tight cohesion. 


\section{ACKNOWLEDGMENTS}

This research is funded by National Foundation for Science and Technology Development, Vietnam under grant number 103.02-2018.34.

\section{REFERENCES}

Adhlakha, N., Yadav, K. L., \& Singh, R. (2015). $\mathrm{BiFeO}_{3}-\mathrm{CoFe}_{2} \mathrm{O}_{4}-\mathrm{PbTiO}_{3}$ composites: Structural, multiferroic, and optical characteristics. Journal of Materials Science, 50(5), 2073-2084.

Ahlawat, A., Satapathy, S., Choudhary, R. J., Shirolkar, M. M., Singh, M. K., \& Gupta, P. K. (2016). Tunable room temperature magnetoelectric response of $\mathrm{SmFeO}_{3} /$ poly (vinylidene fluoride) nanocomposite films. RSC Advances, 6(50), 44843-44850.

Bichurin, M. I., \& Petrov, V. M. (2010). Magnetoelectric effect in magnetostrictionpiezoelectric multiferroics. Low Temperature Physics, 36(6), 544-549.

Burns, G., \& Scott, B. A. (1973). Lattice modes in ferroelectric perovskite: $\mathrm{PbTiO}_{3}$. Physical Review B, 7(7), 3088-3101.

Dileep, K., Loukya, B., Pachauri, N., Gupta, A., \& Datta, R. (2014). Probing optical band gaps at the nanoscale in $\mathrm{NiFe}_{2} \mathrm{O}_{4}$ and $\mathrm{CoFe}_{2} \mathrm{O}_{4}$ epitaxial films by high resolution electron energy loss spectroscopy. Journal of Applied Physics, 116(10), 103505.

Fiebig, M. (2005). Revival of the magnetoelectric effect. Journal of Physics D: Applied Physics, 38(8), R123-R152.

Le, T. M. O., Danh, B. D., \& Nguyen, V. N. (2015). Physical properties of sol-gel lead nickel titanate powder $\mathrm{Pb}\left(\mathrm{Ti}_{1-\mathrm{x}} \mathrm{Ni}_{\mathrm{x}}\right) \mathrm{O}_{3}$. Materials Transactions, 56(9), 1358-1361.

Liu, G., Nan, C. -W., Xu, Z. K., \& Chen, H. (2005). Coupling interaction in multiferroic $\mathrm{BaTiO}_{3}-\mathrm{CoFe}_{2} \mathrm{O}_{4}$ nanostructures. Journal of Physics D: Applied Physics, 38(14), 2321.

Liu, X. -M., Fua, S. -Y., \& Huang, C. -J. (2005). Synthesis and magnetic characterization of novel $\mathrm{CoFe}_{2} \mathrm{O}_{4}-\mathrm{BiFeO}_{3}$ nanocomposites. Materials Science and Engineering $B, 121(3), 255-260$.

Loyau, V., Morin, V., Chaplier, G., LoBue, M., \& Mazaleyrat, F. (2015). Magnetoelectric effect in layered ferrite/PZT composites: Study of the demagnetizing effect on the magnetoelectric behavior. Journal of Applied Physics, 117(18), 184102.

Meinert, M., \& Reiss, G. (2014). Electronic structure and optical band gap determination of $\mathrm{NiFe}_{2} \mathrm{O}_{4}$. Journal of Physics: Condensed Matter, 26(11), 11550.

Moret, M. P., Devillers, M. A. C., Wörhoff, K., \& Larsen, P. K. (2002). Optical properties of $\mathrm{PbTiO}_{3}, \mathrm{PbZr}_{\mathrm{x}} \mathrm{Ti}_{1-\mathrm{x}} \mathrm{O}_{3}$, and $\mathrm{PbZrO}_{3}$ films deposited by metalorganic chemical vapor on $\mathrm{SrTiO}_{3}$. Journal of Applied Physics, 92(1), 468-474. 
Murakami, M., Chang, K. S., Aronova, M. A., Lin, C. L., Yu, M. H., Simpers, J. H., Wuttig, M., Takeuchi, I., Gao, C., Hu, B., Lofland, S. E., Knauss, L. A., \& Bendersky, L. A. (2005). Tunable multiferroic properties in nanocomposite $\mathrm{PbTiO}_{3}-\mathrm{CoFe}_{2} \mathrm{O}_{4}$ epitaxial thin films. Applied Physics Letters, 87, 112901.

Narendra Babu, S., Hsu, J. -H., Chen, Y. S., \& Lin, J. G. (2011). Magnetoelectric response in lead-free multiferroic $\mathrm{NiFe}_{2} \mathrm{O}_{4}-\mathrm{Na}_{0.5} \mathrm{Bi}_{0.5} \mathrm{TiO}_{3}$ composites. Journal of Applied Physics, 109(7), 07D904.

Newnham, R. E. (1986). Composite electroceramics. Ferroelectrics, 68(1), 1-32.

Palneedi, H., Annapureddy, V., Priya, S., \& Ryu, J. (2016). Status and perspectives of multiferroic magnetoelectric composite materials and applications. Actuators, $5(1), 9$.

Pereira, N., Lima, A. C., Lanceros-Mendez, S., \& Martins, P. (2020). Magnetoelectrics: Three centuries of research heading towards the 4.0 industrial revolution. Materials, 13(18), 4033.

Ren, Z., Xu, G., Wei, X., Liu, Y., Hou, X., Du, P., Weng, W., Shen, G., \& Han, G. (2007). Room-temperature ferromagnetism in Fe-doped $\mathrm{PbTiO}_{3}$ nanocrystals. Applied Physics Letters, 91(6), 63106.

Schileo, G. (2013). Recent developments in ceramic multiferroic composites based on core/shell and other heterostructures obtained by sol-gel routes. Progress in Solid State Chemistry, 41(4), 87-98.

Shimada, T., Uratani, Y., \& Kitamura, T. (2012a). Vacancy-driven ferromagnetism in ferroelectric $\mathrm{PbTiO}_{3}$. Applied Physics Letters, 100(16), 162901.

Shimada, T., Uratani, Y., \& Kitamura, T. (2012b). Emergence of ferromagnetism at a vacancy on a non-magnetic ferroelectric $\mathrm{PbTiO}_{3}$ surface: A first-principles study. Acta Materialia, 60(18), 6322-6330.

Shvartsman, V. V., Alawneh, F., Borisov, P., Kozodaev, D., \& Lupascu, D. C. (2011). Converse magnetoelectric effect in $\mathrm{CoFe}_{2} \mathrm{O}_{4}-\mathrm{BaTiO}_{3}$ composites with a coreshell structure. Smart Materials and Structures, 20(7), 75006.

Tsai, C. Y., Chen, H. R., Chang, F. C., Tsai, W. C., Cheng, H. M., Chu, Y. H., Lai, C. H., \& Hsieh, W. F. (2013). Stress-mediated magnetic anisotropy and magnetoelastic coupling in epitaxial multiferroic $\mathrm{PbTiO}_{3}-\mathrm{CoFe}_{2} \mathrm{O}_{4}$ nanostructures. Applied Physics Letters, 102(13), 132905.

Wang, B. Y., Wang, H. T., Singh, S. B., Shao, Y. C., Wang, Y. F., Chuang, C. H., Yeh, P. H., Chiou, J. W., Pao, C. W., Tsai, H. M., Lin, H. J., Lee, J. F., Tsai, C. Y., Hsieh, W. F., Tsai, M. H., \& Pong, W. F. (2013). Effect of geometry on the magnetic properties of $\mathrm{CoFe}_{2} \mathrm{O}_{4}-\mathrm{PbTiO}_{3}$ multiferroic composites. RSC Advances, 3(21), 7884-7983.

Zeng, Z., Wu, H., Zhou, C., Qin, X., He, J., Ji, C., Deng, X., Gao, R. L., Fu, C., Cai, W., Chen, G., Wang, Z., \& Lei, X. (2020). Effect of sintering temperature on 
magnetoelectric properties of $\mathrm{PbTiO}_{3} / \mathrm{NiFe}_{2} \mathrm{O}_{4}$ composite ceramics. Journal of Asian Ceramic Societies, 8(4), 1206-1215.

Zheng, T., Deng, H., Zhou, W., Zhai, X., Cao, H., Yu, L., Yang, P., \& Chu, J. (2016). Bandgap modulation and magnetic switching in $\mathrm{PbTiO}_{3}$ ferroelectrics by transition elements doping. Ceramics International, 42(5), 6033-6038.

Zhou, W., Deng, H., Yu, L., Yang, P., \& Chu, J. (2015). Magnetism switching and band-gap narrowing in Ni-doped $\mathrm{PbTiO}_{3}$ thin films. Journal of Applied Physics, $117(19), 194102$. 